\title{
Effects of a half a millennium winter on a deep lake - a shape of things to come?
}

\author{
DIETMAR STRAILE*, ONUR KERIMOGLU*, FRANK PEETERS*, MARC C. JOCHIMSEN*, \\ REINER KÜMMERLIN†, KARSTEN RINKE* and KARL-OTTO ROTHHAUPT* \\ *Limnological Institute, Department of Biology, University of Konstanz, 78464 Konstanz, Germany, †Institut für Seenforschung, \\ Langenargen, Germany
}

\begin{abstract}
Analyses of the effects of extreme climate periods have been used as a tool to predict ecosystem functioning and processes in a warmer world. The winter half-year 2006/2007 (w06/07) has been extremely warm and was estimated to be a half-a-millennium event in central Europe. Here we analyse the consequences of w06/07 for the temperatures, mixing dynamics, phenologies and population developments of algae and daphnids (thereafter w06/07 limnology) in a deep central European lake and investigate to what extent analysis of w06/07 limnology can really be used as a predictive tool regarding future warming. Different approaches were used to put the observations during w06/07 into context: (1) a comparison of w06/07 limnology with long-term data, (2) a comparison of w06/07 limnology with that of the preceding year, and (3) modelling of temperature and mixing dynamics using numerical experiments. These analyses revealed that w06/07 limnology in Lake Constance was indeed very special as the lake did not mix below $60 \mathrm{~m}$ depth throughout winter. Because of this, anomalies of variables associated strongly with mixing behaviour, e.g., Schmidt stability and a measure for phosphorus upward mixing during winter exceeded several standard deviations the long-term mean of these variables. However, our modelling results suggest that this extreme hydrodynamical behaviour was only partially due to w06/07 meteorology per se, but depended also strongly on the large difference in air temperature to the previous cold winter which resulted in complete mixing and considerable cooling of the water column. Furthermore, modelling results demonstrated that with respect to absolute water temperatures, the model 'w06/07' most likely underestimates the increase in water temperature in a warmer world as one warm winter is not sufficient to rise water temperatures in a deep lake up to those expected under a future climate.
\end{abstract}

Keywords: climate change, Daphnia, Lake Constance, mixing, phenology, phytoplankton bloom, plankton succession, winter sequence

Received 18 August 2009; revised version received 23 November 2009 and accepted 25 November 2009

\section{Introduction}

Climate change is expected to strongly alter the functioning of ecosystems. However, it is difficult to predict in necessary detail the consequences of warming for a specific ecosystem. One possibility to learn about the effects of warming is to study the effects of extreme weather periods. For example, the exceptional heat wave in central Europe during summer 2003 (Schär et al., 2004) was analysed to provide insights about temperature gradients, stratification strengths and oxygen dynamics in a warmer world (Jankowski et al., 2006). The 2003 heat wave not only caused changes in the abiotic conditions in freshwater systems, but was also associated with significant changes in the dynamics of aquatic populations and communities, e.g., exceptional blooms of cyanobacteria in lakes (Jöhnk et al.,

Correspondence: Dietmar Straile, tel. +497531882969 , fax +49 753188 3533, e-mail: Dietmar.Straile@uni-konstanz.de
2008) and dinoflagellates in the ocean (Gomez \& Souissi, 2008), declines in benthic invertebrate species richness (Mouthon \& Daufresne, 2006), as well as severe mass mortality events of fish (Buwal \& Meteoschweiz, 2004; Wegner et al., 2008) and marine benthic invertebrates (Garrabou et al., 2009). Several of these studies suggested that the ecological consequences of this extreme summer may indeed be expected in a warmer climate.

Besides summer also winter meteorological conditions have been shown to have strong and long-lasting effects on the ecology of lakes but also of other ecosystems (Straile \& Stenseth, 2007). Winter conditions can influence survival rates and hence will affect the dispersal potential of invasive species (Thieltges et al., 2004) and/or the size of the 'founder population' of native species for the next growing season (Tonn \& Paszkowski, 1986; Danylchuk \& Tonn, 2006). Finally, in many lakes the end of cold winter conditions which are either associated with ice cover or winter mixis finally 
releases phytoplankton from light limitation and initiates the phytoplankton spring bloom (Weyhenmeyer et al., 1999; Peeters et al., 2007b). The importance of winter and early spring conditions for ecological processes actually explains to a large extent the success of the winter index of the North Atlantic Oscillation as a predictor of ecological state variables and processes (Ottersen et al., 2001; Drinkwater et al., 2003; Mysterud et al., 2003; Straile et al., 2003b; Straile \& Stenseth, 2007). Finally, since warming in the northern hemisphere is expected to be strongest in winter (IPCC, 2007), analysing the consequences of an extreme winter for the development of aquatic systems is important for understanding the possible effects of climate warming on plankton succession.

The winter half-year 2006/2007 (w06/07) was an extreme weather period for Central Europe likely to be the warmest winter during the last 500 years (Luterbacher et al., 2007). Furthermore, the temperatures observed during w06/07 were within the temperature ranges expected with climate change at the end of this century (Beniston, 2007). A comparison with climate predictions based on the IPCC SRES A2 climate scenario, which assumes no reduction in $\mathrm{CO}_{2}$ emissions during this century, suggests that temperatures observed during w06/07 would occur at least during 1 year within a 2-year time period by 2100 (Beniston, 2007). As a consequence of the extreme meteorological conditions, strong phenological anomalies have been observed after w06/07 in terrestrial ecosystems (Luterbacher et al., 2007; Maignan et al., 2008; Rutishauser et al., 2008).

Here we investigate the physicochemical and biological response of a large and deep lake to the extreme conditions of w06/07. Thereby, we use three approaches: (1) we relate monthly means of several state variables during w06/07 with the monthly long-term means of these state variables and calculate how strongly the observations from w06/07 deviate from long-term means. (2) We compare depth resolved data on water temperature, chlorophyll concentration as well Daphnia abundance measured at a high temporal and water-depth resolution measured in w06/07 with data from the preceding winter 2005/2006 (w05/06). (3) We use a hydrodynamical model to simulate the water temperature and compare these simulations with simulations assuming long-term persistence of w05/06 and w06/07 meteorological conditions, respectively. Based on data analysis and numerical experiments, we investigate to which extent the observed effects can be explained by the w06/07 on its own and/or by the sequence of w06/07 following w05/06. Using these three approaches, we do not only discuss the ecological consequences of extreme weather conditions in winter on lake ecosystems but also address the question, which conclusions derived from the observations of an extreme year in fact may serve as a projection of the limnology of deep lakes in a warmer climate.

\section{Study site and methods}

Upper Lake Constance is a large $\left(472 \mathrm{~km}^{2}\right)$, deep $\left(z_{\max }=252 \mathrm{~m}\right)$ and warm-monomictic lake at the northern fringe of the Alps. After the 1950s increased phosphorus inflow into the lake resulted in strong eutrophication, which peaked in the 1970/1980s reaching total phosphorus concentrations around $80 \mu \mathrm{g} \mathrm{L}{ }^{-1}$. Since then phosphorus inflows were strongly reduced and total phosphorus concentrations in the lake have returned now to typical levels $\left(<10 \mu \mathrm{g} \mathrm{L}^{-1}\right)$ before eutrophication. The response of the lake to changes in phosphorus inflows is well documented (see monograph by Bäuerle \& Gaedke, 1998). Likewise, the response of the lake to climate variability was analysed in some detail in recent years (Straile, 2000; Straile et al., 2003a; Peeters et al., 2007a; Peeters et al., 2007b). Model simulations predict strong increases in epilimnetic as well as hypolimnetic water temperatures and an earlier timing of the phytoplankton spring bloom with warming (Peeters et al., 2007a).

The analysis of w06/07 anomalies was based on water properties and water sample concentrations from two sites in Lake Constance (Fig. 1): site C [water temperature, Schmidt stability (Schmidt, 1928), soluble reactive phosphorus (SRP), $\mathrm{O}_{2}$ concentration, phytoplankton biovolume] at the centre of Upper Lake Constance (water depth: $250 \mathrm{~m}$ ), site BM (chlorophyll a concentration, Daphnia abundance) within the Überlinger See, a fjordlike appendix of Upper Lake Constance (water depth: $140 \mathrm{~m}$ ). Seasonal development of water temperatures and stratification patterns at the two sites are very similar as it is possible to very well simulate water temperature dynamics at site BM with a hydrodynamical model calibrated with data from site $\mathrm{C}$ (Peeters et al., 2007b). Air temperatures (AT) were measured at Konstanz (MET in Fig. 1) and provided by the German National Meteorological Service (DWD). From time series of monthly data or monthly averages of data sampled with higher temporal resolution we calculated anomalies for the w06/07 values, e.g., determined how many standard deviations the w06/07 values differed from the long-term mean in the respective months.

The long-term data sets used to calculate the w06/07 anomalies differed in length and dated back to 1964 (water temperature and $\mathrm{O}_{2}$ concentration), 1967 (SRP concentration), 1973 (AT), 1976 (phytoplankton biovolume), 


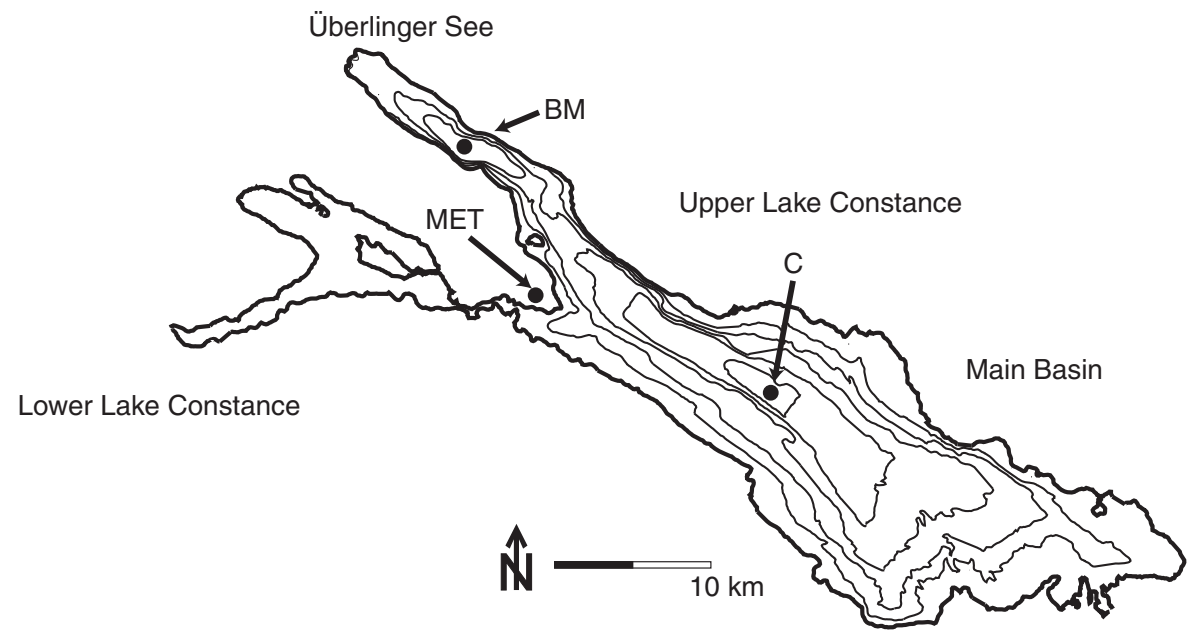

Fig. 1 Location of the two sampling sites (C, BM) within Lake Constance and of the meteorological station (MET).

1979 (Daphnia abundance, but no data in 1983), and 1980 (chlorophyll $a$ concentration, but no data in second half of 1983 and in 1984, 1985). To account for the strong changes in SRP during eutrophication and oligotrophication of Lake Constance, for each sampling date and depth, we calculated the relative SRP concentration as the ratio between the depth-specific SRP and the maximum SRP value of each date. The average relative SRP concentration within the upper $20 \mathrm{~m}$ of the water column (relSRP) was then used as a measure of mixing (Straile et al., 2003a). RelSRP values approaching one indicate homogeneous distribution of SRP throughout the water column and hence the presence of deep-water mixing. We then use the maximum relSRP attained within a specific winter (relSRP $P_{\max }$ ) to quantify the overall mixing intensity of this winter. As the length of the reference period differed between variables, the anomalies are not comparable in a strict sense. However, all the results presented are robust against using different reference periods, e.g., for all variables the period 1980-2006. Further details about sampling methods and sampling frequencies of these long-term data sets can be found in Häse et al. (1998), Kümmerlin (1998), Straile \& Geller (1998) and Straile et al. (2003a).

Samples for the comparison between w05/06 and w06/07 were taken at site BM (Fig. 1). Water temperatures were measured at a high temporal resolution with a thermistor chain (17 thermistors within the upper $20 \mathrm{~m}$ of the water column, 16 thermistors from 20 to $135 \mathrm{~m}$ depth), chlorophyll $a$ samples were taken at distinct depths, i.e., $0,1,2,3,4,5,6,7,8,10,12.5,15$, $17.5,20,22.5,25,30,40,50$ and $60 \mathrm{~m}$. Daphnia was sampled with a Clarke-Bumpus sampler with a vertical haul from $140 \mathrm{~m}$ depth.
Finally, we used a hydrodynamical model, SIMSTRAT (Goudsmit et al., 2002; Peeters et al., 2007b) to evaluate to what extent the physical conditions observed in w06/07 are representative of those to be anticipated with future warming. The model SIMSTRAT simulates vertical turbulent diffusion on the basis of a one-dimensional $k-\varepsilon$ model that is extended by an energy compartment mimicking the energy flux from wind energy to seiche energy and from seiche energy to turbulent kinetic energy and dissipation (Goudsmit et al., 2002; Peeters et al., 2007b). SIMSTRAT calculates energy fluxes across the air/water interface from hourly measurements of wind speed, wind direction, AT, solar radiation, relative humidity and cloud cover. Details on the preparation of the meteorological data for use in the model - e.g., on estimating the wind speed over open water and the solar radiation penetrating the lake surface - are given elsewhere (Peeters $\mathrm{et} \mathrm{al.,}$ 2007b). Based on the energy fluxes across the air/water interface, SIMSTRAT estimates the turbulent kinetic energy, $k$, and the rate of turbulent kinetic energy dissipation, $\varepsilon$, at different depths within the lake. Turbulent diffusivity $K_{\mathrm{z}}$ is estimated from the proportionality $K_{z} \sim k^{2} / \varepsilon$. With respect to the energy fluxes into the seiche compartment of SIMSTRAT, we have slightly modified the original model by assuming that the energy flux from wind to seiche energy increases linearly with the Schmidt stability. Water temperature and density profiles are calculated based on the heat flux across the air-water interface, the short-wave radiation penetrating into the lake and the vertical profile of $K_{\mathrm{z}}$. Heat fluxes due to long- and short-wave radiation, evaporation and conduction are simulated using empirical relationships. Light attenuation coefficients were based on measured chlorophyll concentrations. 
In SIMSTRAT, which uses an implicit algorithm to solve the model equations, an internal vertical spatial resolution of $0.25 \mathrm{~m}$ and a time step of $10 \mathrm{~min}$ were used. The model was calibrated by adjusting seven constant model parameters to minimize the root mean square error between simulated and measured water temperatures during the 6-year time period from 1979 to 1984 . Simulations were run continuously to predict vertical profiles of temperature and turbulent diffusivity. In this study, we first tested if the model was able to simulate the temperature development during the two winters, i.e., w05/06 and w06/07. Then we used the model to conduct several numerical experiments (1) to analyse the importance of summer and autumn 2006 meteorology for w06/07 dynamics (in the following exchange simulations), (2) to model the equilibrium winter dynamics which would be reached after forcing the model repeatedly with an annual meteorology file including w06/07 or w05/06 meteorology, (3) to test whether the extreme w06/07 limnology was caused solely by the meteorology of w06/07 or resulted from the specific sequence of winters, e.g., the cold w05/06 preceding the warm w06/07. In the first experiment (thereafter exchange simulations), we exchanged the meteorology of certain time periods from summer and autumn 2006 with meteorology from corresponding time periods from summer and autumn 2005 in order to test which part of summer/autumn 2006 meteorology was crucial for w06/07 water temperature dynamics. In the second experiment (equilibrium simulations), we estimated the equilibrium winter dynamics of w06/07 by forcing the model repeatedly with the meteorology from September 1, 2006 to August 31, 2007 , i.e., considering a repeated sequence of a single year that includes w06/07 until the equilibrium seasonal courses of water temperatures were obtained (eq06/ 07). Thereafter the model was repeatedly forced with the meteorology between September 1, 2005 and August 31, 2006 to study the hypothetical equilibrium seasonal water temperatures of this time period that includes w05/06 (eq05/06). In the third experiment (sequence simulations), we generated 27 artificial meteorology files all starting from January 1, 1979 but continuing until October 1979, 31 (artificial meteorology 1), October 31, 1980 (artificial meteorology 2), ... and respectively, October 31, 2005 (artificial meteorology 27). Each of these 27 meteorologies were extended with an additional winter: the meteorology from November 1, 2006 to March 31, 2007. We used each of these artificial meteorologies to force the hydrodynamic model and calculated the winter mixing duration during the last winter, i.e., that forced with w06/07 meteorology. These mixing durations were then compared with the mixing duration during the winters obtained from the standard simulation forced with unmodified meteorology files. The duration of the winter mixing period was estimated as the number of days with a maximum temperature difference within the entire water column of less than a threshold of $0.25^{\circ} \mathrm{C}$.

\section{Results}

\section{W06/07 anomalies}

AT at Konstanz during w06/07 but also in spring 2007 were exceptionally warm (Fig. 2) resulting in exceptionally large water temperature anomalies from November to March during w06/07. As a consequence of high surface temperatures, Schmidt stability anomalies $\geq 2$, i.e., a deviation from the mean $\geq 2$ standard deviations, were observed from December towards April, with anomalies even exceeding four in February and March. This reflects the fact that w06/07 was the first winter within a $>40$-year time series with no mixing below $60 \mathrm{~m}$ water depth. These stability anomalies were associated with strong negative upper water column relSRP anomalies around three from January through March. In contrast, no large deep-water $\mathrm{O}_{2}$ anomalies were observed. Also, anomalies of chlorophyll $a$, phytoplankton biovolume and Daphnia abundance were small compared with e.g., anomalies of water temperature, Schmidt stability and relSRP. Although they were measured at two different sampling sites (BM and C in Fig. 1, respectively), chlorophyll $a$ and phytoplankton biovolume anomalies were similar, which further supports that at the scale of this investigation the differences between the two sampling sites can be considered as negligible.

\section{W06/07 compared with w05/06}

W06/07 was preceded by the rather cold w05/06 ranking third coldest in our time series based on average winter AT and seventh coldest based on upper water layer $(0-20 \mathrm{~m})$ temperatures. As w06/07 was clearly the warmest winter in both, air and water temperature records, there was a striking temperature difference between the 2 years, which needs to be taken into account when analysing the ecological implications of w06/07. As a consequence of low AT, w05/06 was characterized by a long period of homeothermy throughout the water column lasting 3 months, i.e., from January until the end of March and consequently a considerable cooling of hypolimnetic water temperatures (Fig. 3). In contrast, during w06/07 no period of homeothermy was observed and mixing during February and March did not extend to depths below the upper $60 \mathrm{~m}$ of the water column. The years differed 


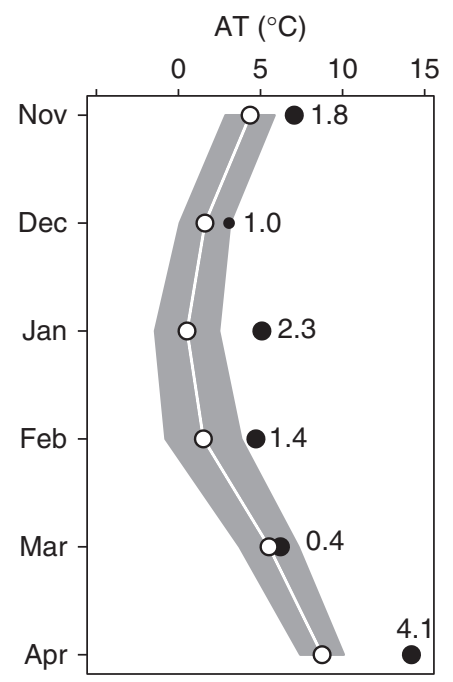

Rel. SRP (\%)

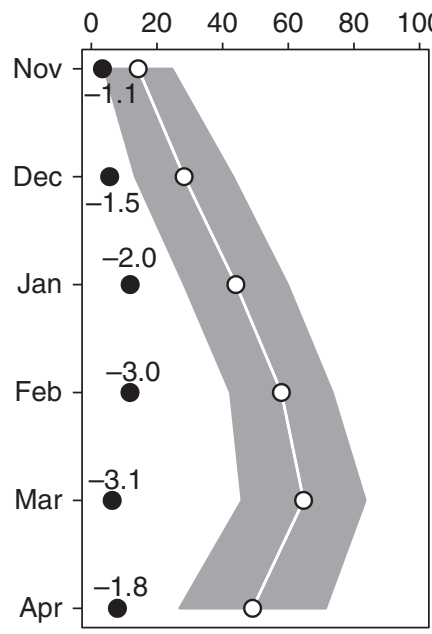

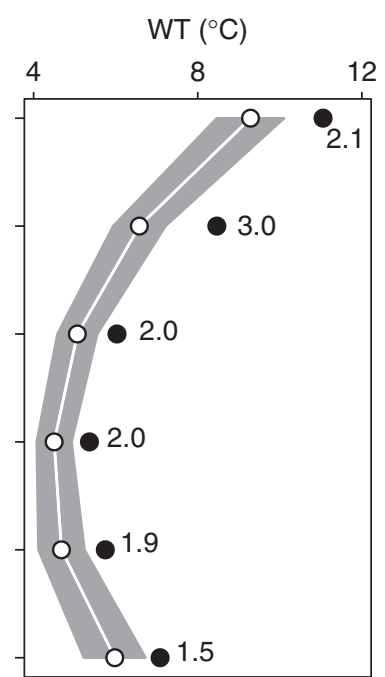

Chl $a\left(\mu \mathrm{g} \mathrm{L}^{-1}\right)$

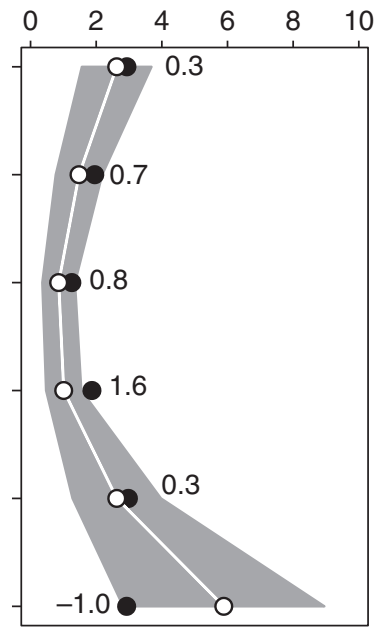

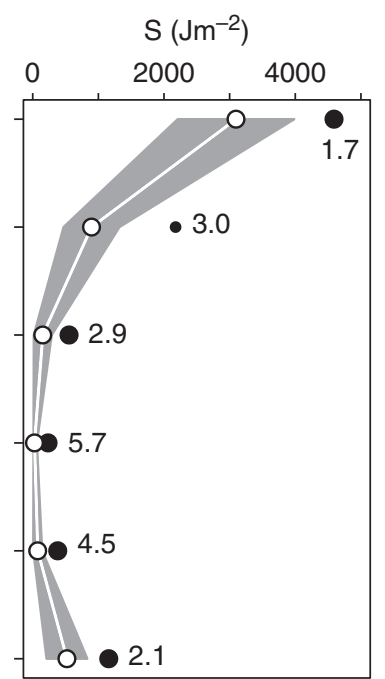
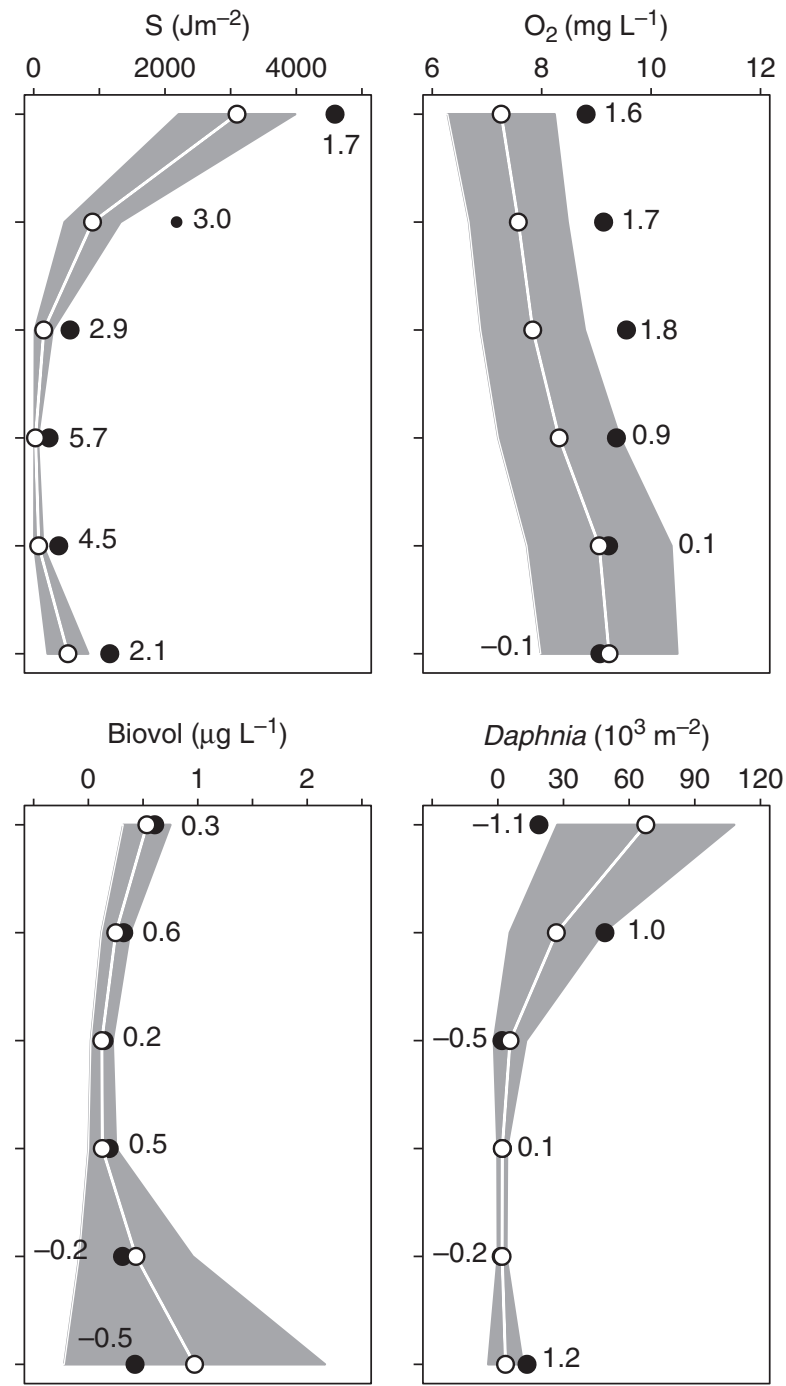

Fig. 2 Temporal developments of winter half-year 2006/2007 (w06/07) state variables as compared with the long-term temporal development. White circles represent the long-term mean, the grey area \pm 1 standard deviation around the mean; the black circles represent the values for w06/07. Numbers indicate how many standard deviations w06/07 values deviate from the long-term means in the respective months. The following state variables are shown: AT, air temperature; WT, water temperature $(0-20 \mathrm{~m} \mathrm{depth);}, \mathrm{Schmidt}$ stability; $\mathrm{O}_{2}$, oxygen concentration in deep water (200-250 m depth); relSRP, relative soluble reactive phosphorus (SRP) concentrations in upper water layers (0-20 m depth); chlorophyll $a$ and phytoplankton biovolume concentrations (0-20 m depth), Daphnia abundance (1000 individuals $\mathrm{m}^{-2}$ integrated over a depth of $140 \mathrm{~m}$ ).

also markedly in the onset of surface warming which was advanced in 2007 as compared with 2006 by more than 1 month (Figs 3 and 4). As a consequence of differences in mixing regime, chlorophyll $a$ dynamics also differed strongly between years (Figs 3 and 4). Low chlorophyll $a$ concentrations $\left(0.2 \mu \mathrm{g} \mathrm{L}^{-1}\right)$ were observed especially during January and February 2006, whereas the lack of complete mixing resulted in elevated upperwater layer chlorophyll $a$ concentration throughout w06/07. Furthermore, in February and March elevated chlorophyll $a$ concentration extended down to a depth of approximately $50 \mathrm{~m}$, i.e., the depth of the mixed layer (Fig. 3). Bloom development was strongly advanced in 2007 as compared with 2006, with an early bloom developing already in mid-March, whereas it took until the end of April until similar surface concentration were obtained in 2006. However bloom onset in 2007 (March 13) defined as the first sampling date where chlorophyll a concentrations surpassed $3 \mu \mathrm{gL}^{-1}$ (Peeters et al., 2007a) did not show strong anomalies as it was only 1.2 standard deviations earlier than the average bloom onset in the long-term record (April $1 \pm 16.9$ days). 

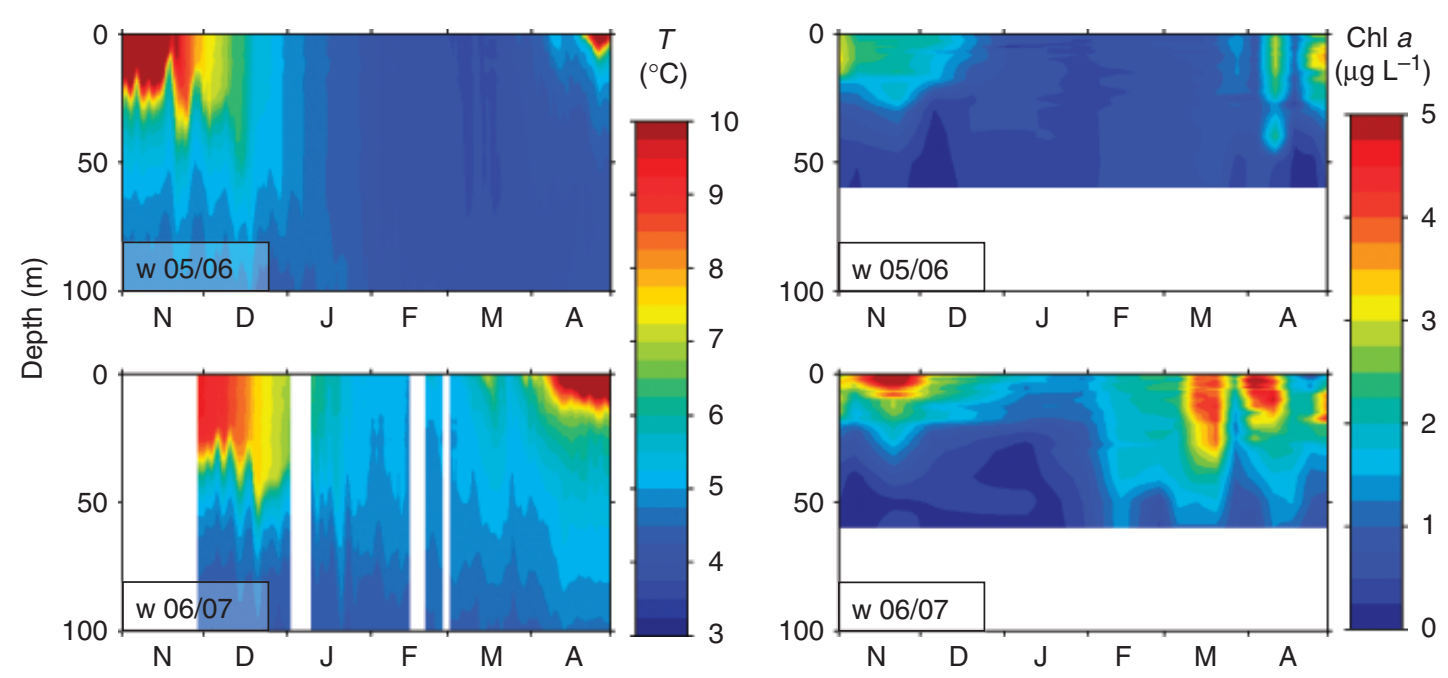

Fig. 3 Comparison of water temperature (left panel) and chlorophyll $a$ dynamics (right panel) during winter half-year 2005/2006 (w05/ 06) and winter half-year 2006/2007 (w06/07) at station BM. No water temperature data for November 2006 and no chlorophyll $a$ data below $60 \mathrm{~m}$ water depth are available.

Daphnia dynamics did not differ substantially during the winter period up to the end of March in w05/06 and w06/07 (Fig. 4), despite the much higher chlorophyll $a$ concentrations in w06/07 than in w05/06. However, the timing of minimum (April 18, 2006 vs. March 27, 2007: 22 days) and maximum (May 30, 2006 vs. May 2, 2007: 28 days) Daphnia abundances was considerably earlier in 2007 as compared with 2006 resulting in a temporal forward shift of spring growth of Daphnia populations. In both years, the timing of the minimum was at the last sampling date before water temperatures finally rose above $6^{\circ} \mathrm{C}$ (April 24, 2006 vs. March 31, 2007: 24 days). However, in contrast to the only slight forward shift of the onset of the algal bloom, the timing of the Daphnia maximum in 2007 was the earliest one in a 28-year time series, 2.2 standard deviations earlier than the longterm average timing during 1979-2006 (June $9 \pm 16.9$ days). Note also, that both, Daphnia minimum and Daphnia maximum abundances were rather similar in both years.

\section{Modelling}

The hydrodynamical model simulating water temperatures over a 29-year time period starting in 1979 adequately predicted the key differences in thermal stratification observed during the time periods w05/06 and w06/07: the long period of homeothermy of w05/06 as compared with incomplete mixing during w06/07 as well as the advanced onset of the stratification in 2007 (Fig. 5). However, the depth of the mixed layer in w06/07 was approximately $40 \mathrm{~m}$ deeper in the model as compared with the observed values.

Long-term simulation with the meteorology of w05/ 06 (eq05/06) did not result into strong differences as compared with the simulation of w05/06: deep-water temperatures were slightly reduced and the period of full mixing started approximately half-month earlier. In contrast, long-term simulation with the meteorology of w06/07 revealed striking differences as compared with the simulations for w06/07: water temperatures were strongly elevated and approached $7{ }^{\circ} \mathrm{C}$ when homeothermy was established. In this state, the warming of deeper water layers allowed complete mixing in the eq06/07 simulations. Interestingly, hydrodynamical modelling suggests that it would take five w06/07 winters to reach the new equilibrium shown in Fig. 5. Likewise, five w05/06 winters would be needed to cool down the lake again to the situation before w06/07. Note also, that the equilibrium seasonal water temperature dynamics of the two periods September 1, 2005-August 31, 2006 vs. September 1, 2006-August 31, 2007 do hardly differ regarding their maximum temperatures obtained during summer, but strongly in the winter minimum temperatures. This suggests that the crucial difference in meteorological conditions between these two periods is during the winter half-year. This conclusion was further supported by our exchange simulations. These simulation experiments suggested that the hydrodynamical key characteristics of w06/07, i.e., no deep-water mixing and elevated water temperatures depend on the meteorology from November 2006 onwards: An exchange of the meteorology from June 1, 

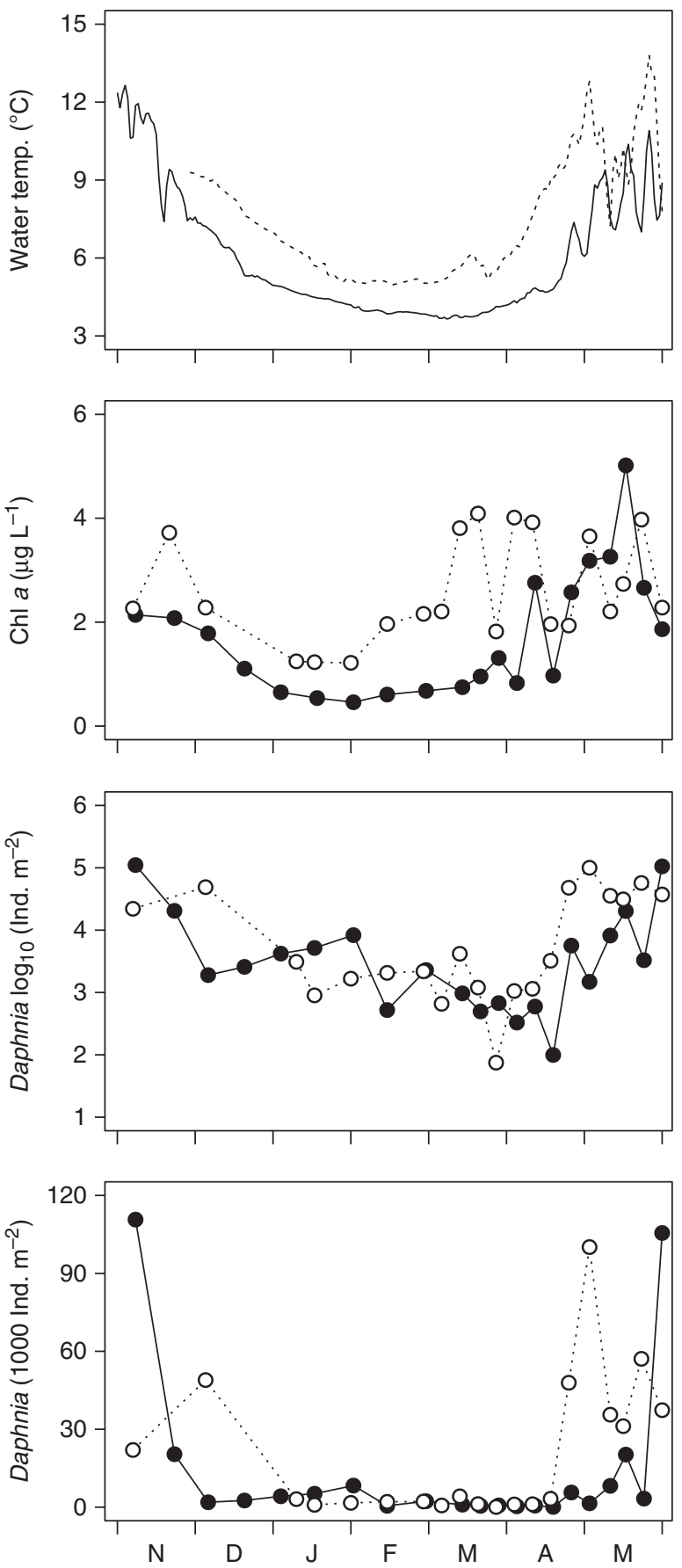

Fig. 4 Development of (a) water temperature, (b) chlorophyll $a$ and (c, d) Daphnia abundances during winter half-year 2005/ 2006 (w05/06) (continuous line, filled circles) as compared with winter half-year 2006/2007 (w06/07) (hatched line, open circles) at site BM. Water temperatures and chlorophyll $a$ concentrations represent upper water column $(0-20 \mathrm{~m})$ averages, whereas Daphnia abundances are integrated over the whole water column $(0-140 \mathrm{~m})$. Daphnia abundances are presented on arithmetic and logarithmic scales as the two different scales are necessary to present both winter dynamics as well as the spring growth phase.
2006 to October 31, 2006 with June 1, 2005-October 31, 2005 did hardly change the simulations for w06/07, whereas an exchange of November 2006 with November 2005 resulted in whole water column homeothermy (see supporting online information).

As mixing dynamics showed the strongest anomalies we examined the relationship between winter AT and mixing strength expressed as relSRP $P_{\max }$ in detail. The relationship between average (November-March) winter AT and winter mixing was nonlinear (Fig. 6a). A piece-wise regression suggests a change point at an AT of $2.3 \pm 0.6^{\circ} \mathrm{C}$ (SE). Below this threshold no relationship between relSRP ${ }_{\max }$ and AT was apparent $(r=0.12$, ns, $n=10)$, whereas above the threshold a strong inverse relationship existed ( $r=-0.64, P<0.001, n=16)$. However, the residuals of relSRP $P_{\max }$ from the piece-wise regression model in years with AT below $2.3^{\circ} \mathrm{C}$ were related to the AT of the previous year (Fig. 6b; $r=0.6$, $P<0.09, n=9)$ and to the deep-water temperatures in November, i.e., at the start of the respective winter (Fig. 6c; $r=0.64, P<0.05, n=10$ ). Residual relSRP ${ }_{\max }$ above $2.3^{\circ} \mathrm{C}$ was neither related to AT of the previous winter (Fig. 6d) nor to hypolimnetic water temperatures in November (Fig. 6e).

Average mixing duration in standard simulations was $62.4 \pm 3.7$ (SE) days (Fig. 7). Modelled mixing duration in the standard simulation was significantly related to data derived mixing strength as estimated from relSRP ${ }_{\max }(r=0.6, P<0.001, n=28)$. W06/07 meteorology in sequence simulations resulted in a mixing duration of $33.8 \pm 3.4$ (SE) days, i.e., lead to a reduction by $28.6 \pm 4.4$ (SE) days. W06/07 meteorology would have resulted in five sequences with zero mixing, whereas in our standard simulations only during the sequence $\mathrm{w} 05 / 06 \rightarrow \mathrm{w} 06 / 07$ zero mixing was predicted. On the other hand, sequence simulations suggest that in 23 out of 28 sequences (82\%) w06/07 on its own would not have resulted in a lack of mixing. This exemplifies the importance of the sequence of winter meteorology for the extreme mixing conditions during w06/07. Using another threshold value instead of the water column temperature difference $\leq 0.25^{\circ} \mathrm{C}$ as a criterion for full mixing does change the absolute number of mixing days but not the difference between standard and experimental simulations.

\section{Discussion}

The winter 2006/2007 had striking effects on the hydrodynamics and ecology of Lake Constance. However, the possibility of using the conditions and dynamics during 2006/2007 as a blueprint for those expected with global warming will depend strongly on the state variables and processes that are actually considered: for some 

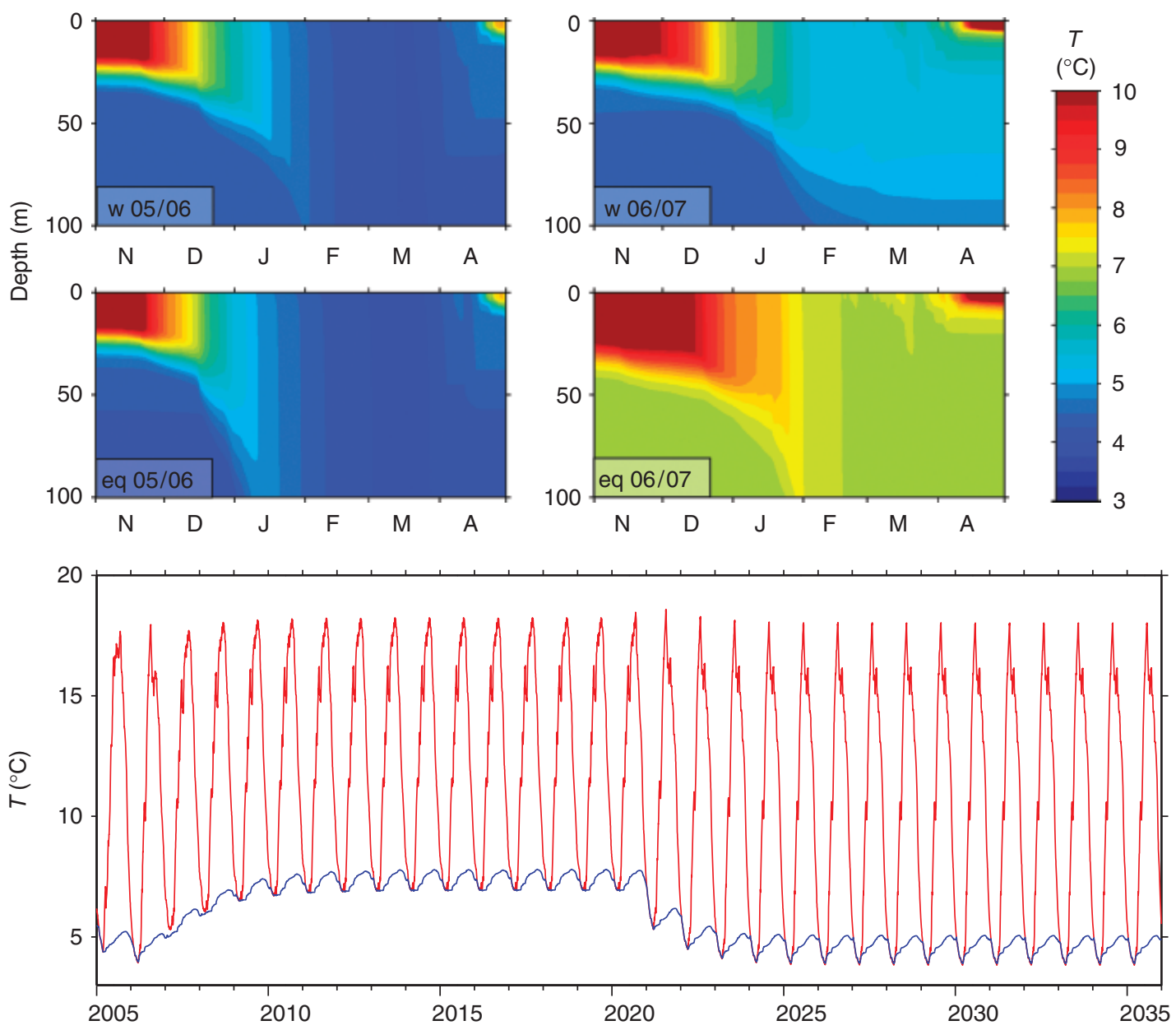

Fig. 5 A hydrodynamical simulation experiment on the short vs. long-term effects of winter conditions. Upper panel: (1) Simulated water temperatures during the winters of 2005/06 and 2006/07. Middle panel: Simulated equilibrium water temperatures for the two winters which would have been obtained after repeatedly using the meteorological conditions between September 1, 2005-August 31, 2006 (eq05/06) and September 1, 2006-August 31, 2007 (eq06/07), respectively (equilibrium simulations). Lower panel: Long-term development of upper (0-20 m, red line) and lower (20-250 m, blue line) water column temperatures assuming that winter half-year 2006/2007 (w06/07) would be the norm until September 2020 and w05/06 from September 2020 onwards. The simulations were driven with the following meteorology: between September 1, 2007 and August 31, 2020, the meteorology of September 1, 2006-August 31, 2007 was repeated. Between September 1, 2020 and December 31, 2035, the meteorology of September 1, 2005-August 31, 2006 was repeated.

variables (e.g., plankton phenology) w06/07 may indeed be a glimpse for future warming, however, changes in other state variables and/or processes may be less strong (e.g., mixing behaviour) or even stronger (e.g., water temperature) in a warmer climate than the changes observed from w05/06 towards w06/07.

Partially, anomalies calculated for chlorophyll $a$, algal biovolume and Daphnia abundance may also be influenced by changes in the trophic status of the lake. As both, algal and Daphnia abundances have declined with oligotrophication (Anneville et al., 2005, D. Straile, unpublished data), low positive or even negative anomalies during w06/07 may be due to the response to oligotrophication. However, calculation of anomalies based on detrended data (results not shown) did not suggest a strong underestimation of climate related w06/07 anomalies due to the confounding effects of oligotrophication. This supports previous results that especially during winter algal and zooplankton population may be more limited by light and low temperatures, respectively, than by nutrients or food availability (Peeters et al., 2007b; Schalau et al., 2008).

The comparison of w06/07 with w05/06 is not confounded by changes in trophic status as the winter phosphorus concentration integrated over the total water column was similar in the two adjacent years. Rather, the comparison emphasizes the importance of meteorological forcing for the ecology of a large and 

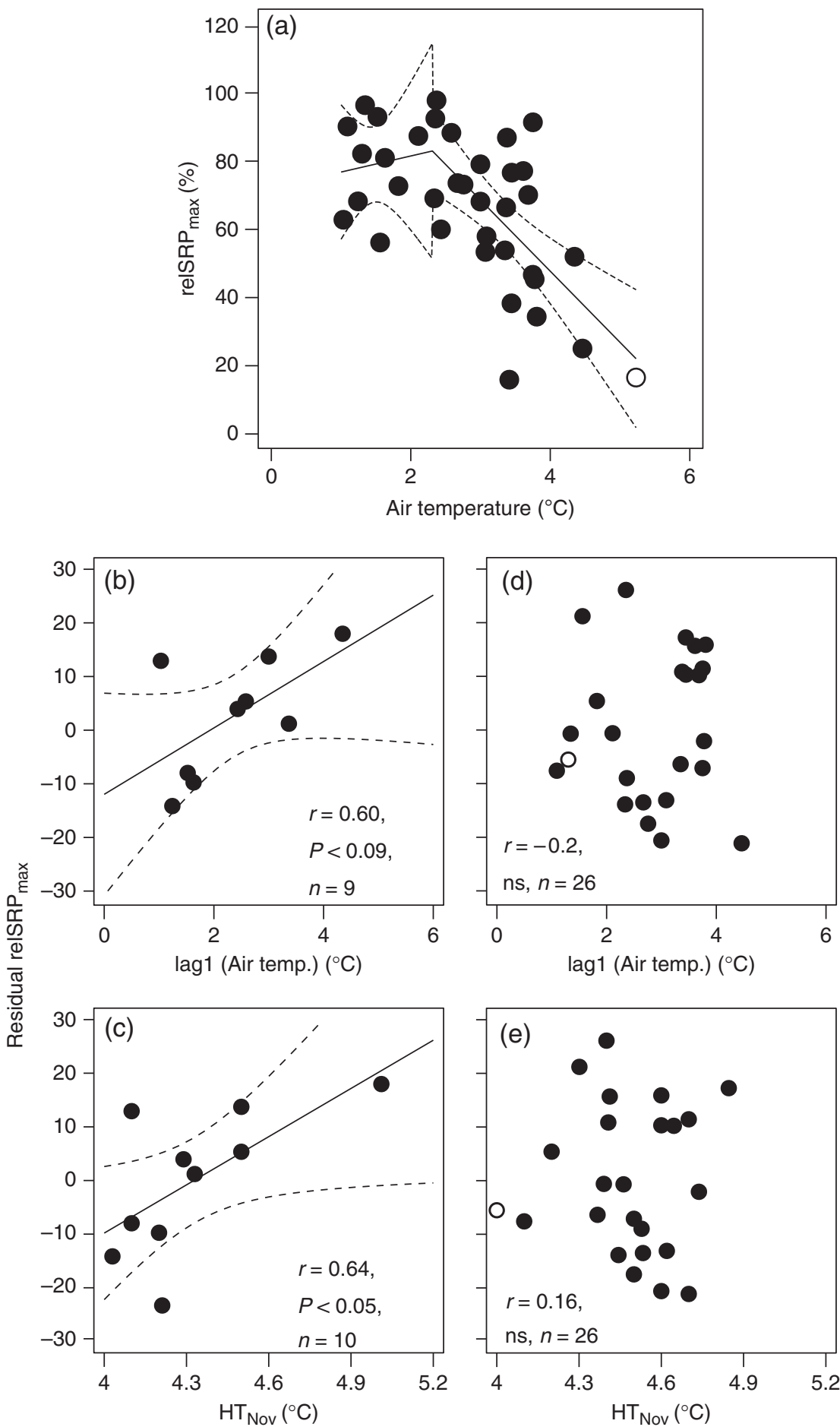

Fig. 6 (a) Relationship of winter mixing intensity expressed as the maximum relative soluble reactive phosphorus (SRP) concentration in a specific winter to the average (November-March) air temperature (AT). The fit is a piecewise linear regression which suggests a change point at $\mathrm{AT}=2.3( \pm 0.65 \mathrm{SE})^{\circ} \mathrm{C}$. The regression equations are $y=71.1+4.7 \times x$, and $y=131.5-20.9 \times x$ below and above the change point, respectively. Overall model fit is $F_{4,32}=8.47, P<0.0003$. ( $\mathrm{b}$ and c) Relationships between the residuals of the piecewise regression model below the change point with AT from the preceding winter, and average November deep-water temperatures (below $100 \mathrm{~m}$ ), respectively, (d and e) relationships between the residuals of the piecewise regression model above the change point with AT from the preceding winter, and November deep-water temperatures, respectively. Winter half-year 2006/2007 (w06/07) is indicated as an open circle and is included in statistical analyses. 


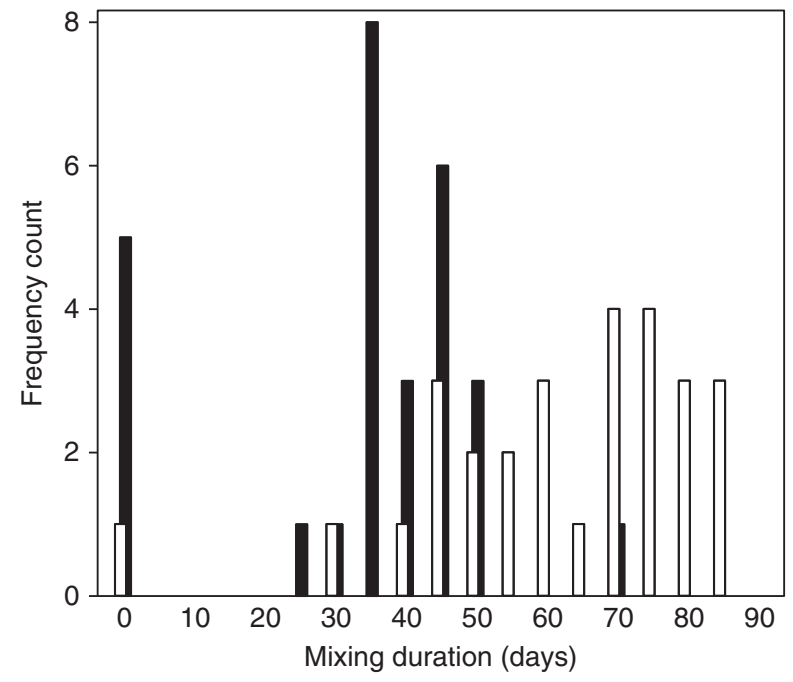

Fig. 7 Frequency of winter mixing duration in the standard simulation in which the historical sequence of winters was maintained (white bars) and in all winter half-year 2006/2007 (w06/07) of the sequence simulations (black bars). Winter mixing duration was estimated as the number of days during winter in which the maximum temperature difference in the water column was $<0.25{ }^{\circ} \mathrm{C}$. For further details, see 'Materials and methods' sections.

deep lake. Whereas the cold w05/06 caused a long period of homeothermy, mixing, and cooling of the complete water body down to $4{ }^{\circ} \mathrm{C}$, mild w06/07 cooled down upper water layers $(0-20 \mathrm{~m})$ to only $5.2^{\circ} \mathrm{C}$. As deep-water temperatures during w06/07 still were around $4{ }^{\circ} \mathrm{C}$, the density gradient between upper (lighter) and lower (heavier) water layers prevented mixing during w05/06 with consequences for e.g., upward mixing of nutrients, downward mixing of oxygen and phytoplankton growth. As phytoplankton growth during winter in a deep lake is strongly reduced by mixing (Peeters et al., 2007b), the absence of deep-water mixing during w06/07 caused enhanced chlorophyll $a$ concentrations down to the mixing depth of approximately $40-60 \mathrm{~m}$. Striking differences between these two winters were also observed in regard to the microbial plankton (Kamjunke et al., 2009).

The comparison between plankton developments in 2007 vs. 2006 strongly supports previous modelling results suggesting that algal development in Lake Constance depends largely on mixing dynamics (Peeters et al., 2007b) whereas Daphnia development during spring is strongly controlled by water temperatures but much less by food availability (Schalau et al., 2008). Furthermore, these data support the model prediction (Schalau et al., 2008) that an earlier temperature increase will change the timing of minimum and max- imum Daphnia abundances but not the height of the maxima. The change in the timing of maximum abundances resulting from faster growth of Daphnia in warmer waters in turn leading to an earlier overexploitation of the algal food (Schalau et al., 2008). While average chlorophyll a concentrations during April 2007 did not differ from those during March 2007 water temperatures were still below $6{ }^{\circ} \mathrm{C}$ in March but increased strongly during April. This suggests that the increase in Daphnia numbers during April 2007 was predominantly caused by the increase in water temperatures.

Both, anomaly calculations as well as hydrodynamical modelling suggest that the specific sequence of winters, i.e., cold w06/07 followed by warm w06/07, is important for understanding the response of deep Lake Constance to w06/07. Largest anomalies were observed for variables related to winter mixing, e.g., Schmidt stability and relSRP. The specific sequence of winters resulted in a large temperature difference in w06/07 between rather warm surface temperature and still cold deep-water temperatures remaining from the last significant cooling during w05/06. The large vertical temperature difference within the water column caused large w06/07 Schmidt stability anomalies and relSRP anomalies in the upper water layers. The latter are primarily caused by the absence of up-ward mixing of SRP during w06/07. Additionally, enhanced uptake of SRP due to enhanced phytoplankton biomass throughout w06/07 possibly further reduced relSRP. Absence of mixing in w06/07 did not result in large hypolimnetic $\mathrm{O}_{2}$ anomalies. However, during w06/07 $\mathrm{O}_{2}$ anomalies declined from a positive anomaly of 1.8 in January 2007 - still due to full mixing and deep-water oxygen replenishment during w05/06 - towards 0 in March 2007 reflecting the absence of downward mixing of $\mathrm{O}_{2}$. The w06/07 hypolimnetic $\mathrm{O}_{2}$ temporal development is hence in contrast to the long-term average temporal hypolimnetic $\mathrm{O}_{2}$ development during winter in Lake Constance, which is characterized by an increase of $\mathrm{O}_{2}$ concentrations (Fig. 2) due to late winter mixing. Nevertheless, the absence of winter mixing in 1 year does not cause large hypolimnetic $\mathrm{O}_{2}$ anomalies because oxygen depletion in the deep water of Lake Constance appears to be low due to its oligotrophic state. However, oxygen depletion can result in deep lakes from a series of warm winters causing a saw-tooth like development of deep-water temperatures and a continuous decline of hypolimnetic $\mathrm{O}_{2}$ concentrations (Livingstone, 1997; Straile et al., 2003a).

Recent climate change scenarios for winter mixing and the onset of stratification in Lake Constance predicted that warming should result in an earlier phytoplankton spring bloom and in a shorter duration but not 
a complete absence of the winter mixing period (Peeters et al., 2007a). The complete absence of deep-water mixing observed during w06/07 seems to suggest that the reality of warming has already outrun the projections from scenario simulations. However, the comparison of the w06/07 hydrodynamical simulations with the eq06/07 hydrodynamical simulation shows that the strong effect of w06/07 on the mixing regime is at least partially due to the fact that w06/07 was preceded by the rather cold w05/06. The latter resulted in rather cool hypolimnetic waters and w06/07 apparently was not severe enough to cool upper water layer temperatures down to those in the hypolimnion, i.e., to reach homeothermy. In the eq06/07 simulations hypolimnetic temperatures have increased up to $7.5^{\circ} \mathrm{C}$ and in this case, w06/07 meteorological conditions would result in homeothermy and winter mixing. The complex relationship between winter AT sequences and mixing strength was also revealed by the nonlinear relationship between average winter AT and our measure of mixing strength $\left(\right.$ relSRP $\left.P_{\max }\right)$. Warm winters clearly decreased relSRP $_{\text {max }}$ as a warm winter decreases the likelihood to cool upper water layers down to hypolimnetic temperatures, i.e., to reach homeothermy. In contrast, average AT below $3{ }^{\circ} \mathrm{C}$ always resulted in relSRP $P_{\text {max }}$ larger than $50 \%$. In these years, relSRP $\max _{\max }$ seems to be partially related to the AT of the previous winter and consequently to hypolimnetic water temperatures in November. A warm previous winter results in a warmer hypolimnion throughout the present winter (Straile et al. 2003a,b) thereby increasing the likelihood of homeothermy. Hence, winter mixing strength in a deep lake seems to be strongly influenced by AT of the current and the previous winter. However, high temperatures in the current winter decrease the likelihood of homeothermy whereas high temperatures in the previous winter increase the likelihood of homeothermy. While the previous winter may have a strong influence on the mixing dynamics of the current winter (Fig. 7), the previous summer is much less likely to have a strong influence (see 'exchange simulations' in supporting online information). This is because variability in summer meteorology mainly influences upper water layer temperatures but hardly the temperatures of the large volumes of hypolimnetic water. As a consequence, summer AT will not have a similarly long lasting effect on stratification as winter AT, which influence the temperatures of the hypolimnion.

Statistical analysis of data can solely not answer the question whether the influence of a warm winter on mixing and plankton growth is due to the AT of the warm winter alone or is supported by the specific sequence of this winter, as a warm winter also increases the probability that there is a large temperature differ- ence between two successive winters. However, sequence simulations showed that although w06/07 would have reduced mixing duration considerably, w06/07 would have resulted in a complete loss of mixing only in $18 \%$ of the sequences examined, whereas in $82 \%$ of winters the temperature difference between successive winters was not large enough to prevent mixing. This suggests that if we take w06/07 as a model for the effects of climate warming on winter mixing and its associated consequences, we would overestimate the effects of a warmer climate on a deep lake. On the other hand, a large difference in temperatures between two consecutive winters may be expected to occur more often in a warmer world as models predict increasing temperature variability in the next century (Schär et al., 2004). In conclusion, w06/07 most likely overestimates the consequences of a warmer climate for winter mixing, although the frequency and duration (Peeters et al., 2007a) of winter mixing in the future will likely be reduced as compared to the 20th century.

Regarding absolute water temperature in the epilimnion and especially in the hypolimnion w06/07 underestimates the effects of warming. One warm winter in a deep lake is not sufficient to strongly heat up the entire water column. The eq06/07 simulations suggested that it would need at least five repetitions of w06/07 meteorology for the lake to reach a new equilibrium in regard to winter water temperatures and mixing regime. This number should however be regarded as a minimum estimate as the w06/07 simulations showed that the model tends to overestimate the depth of the mixed layer during winter which suggests that vertical turbulent diffusivity was somewhat too strong in the simulations. A reduced turbulent diffusivity in the model would result in a longer transition period towards a new equilibrium.

Nevertheless, in a generally warmer climate with repeated winter conditions as in w06/07 epilimnetic and hypolimnetic water temperatures are predicted to increase beyond the temperatures observed during a single extreme winter (see eq06/07 simulations and Peeters et al., 2007a). Especially, the predicted unprecedented warming of deeper water layers may have striking consequences for species which use deeper water layers within a part of their life cycle. For example, in Lake Constance eggs of the dominant planktivorous fish (Coregonus lavaretus) develop on the surface of and planktonic copepods (Cyclops vicinus) diapause within deep hypolimnetic sediments (Straile et al., 2007; Seebens et al., 2009). Hence, strongly increased hypolimnetic water temperatures may cause a mismatch of fish larvae and copepods emerging from the hypolimnion with their respective epilimnetic food sources. In addition deep-water warming is also of concern 
regarding hypolimnetic oxygen concentrations as increased water temperatures may lead to an increase in the rate of oxygen depletion within the water column and the sediment.

To conclude, the comparison of w06/07 limnology with w05/06 limnology, long-term data and simulation results revealed a complex answer to our question: is w06/07 limnology also a shape of the limnology expected to come with warming in a deep lake? The answer depends on the state variables and processes considered: regarding the advances in phenology of e.g., the phytoplankton bloom and Daphnia spring development, w06/07 may indeed be typical for a warmer world. However, the reduction in vertical mixing indicated by the observations from warm winter w06/07 was very strong because w06/07 was preceded by the rather cold w05/06 and most likely will be less severe in a generally warmer world. With respect to absolute water temperatures, w06/07 most likely underestimates the increase in water temperature in a world as is predicted by IPCC scenarios. Consequently, the interpretation of observations from extreme winters as indicators of the consequences of climate warming for lakes ecosystems must be treated with great care, especially in deep lakes where the time scales of changes in abiotic conditions e.g., deep-water heat content, and their consequences on biota are substantially longer than the duration of the extreme event.

\section{Acknowledgements}

We thank Max Tilzer and Walter Geller (Limnological Institute, University of Konstanz) as well as Henno Rossknecht and Harald Hetzenauer (Institut für Seenforschung, Langenargen) and the German National Meteorological Service (Deutscher Wetterdienst) for providing limnological and meteorological long-term data. Two reviewers provided insightful comments which substantially improved this manuscript. Financial support was given by the University of Konstanz and the Deutsche Forschungsgemeinschaft (project PE 701/2-1 within the AQUASHIFT programme, SPP 1162).

\section{References}

Anneville O, Gammeter S, Straile D (2005) Phosphorus decrease and climate variability: mediators of synchrony in phytoplankton changes among European perialpine lakes. Freshwater Biology, 50, 1731-1745.

Bäuerle E, Gaedke U (1998) Lake Constance - characterization of an ecosystem in transition. Archives of Hydrobiology Special Issues on Advanced Limnology, 53, 1-610.

Beniston M (2007) Entering into the "greenhouse century": recent record temperatures in Switzerland are comparable to the upper temperature quantiles in a greenhouse climate. Geophysical Research Letters, 34, L16710, doi: 10.1029/2007GL030144.

Buwal, BWG, Meteoschweiz (2004) Auswirkungen des Hitzesommers 2003 auf die Gewässer. Bundesamt für Umwelt, Wald und Landschaft.Schriftenreihe Umwelt, 369, $1-174$

Danylchuk AJ, Tonn WM (2006) Natural disturbance and life history: consequences of winterkill on fathead minnow in boreal lakes. Journal of Fish Biology, 68, 681-694.

Drinkwater KF, Belgrano A, Borja A et al. (2003) The response of marine ecosystems to climate variability associated with the North Atlantic oscillation. In: The
North Atlantic Oscillation (eds Hurrell JW, Kushnir Y, Ottersen G, Visbeck M), pp. 211-234. American Geophysical Union, Washington, DC.

Garrabou J, Coma R, Bensoussan N et al. (2009) Mass mortality in northwestern Mediterranean rocky benthic communities: effects of the 2003 heat wave. Global Change Biology, 15, 1090-1103.

Gomez F, Souissi S (2008) The impact of the 2003 summer heat wave and the 2005 late cold wave on the phytoplankton in the north-eastern English channel. Comptes Rendus Biologies, 331, 678-685.

Goudsmit GH, Burchard H, Peeters F, Wuest A (2002) Application of k-epsilon turbulence models to enclosed basins: the role of internal seiches. Journal of Geophysical Research-Oceans, 107, 3230.

Häse C, Gaedke U, Seifried A, Beese B, Tilzer MM (1998) Phytoplankton response to re-oligotrophication in large and deep lake Constance: photosynthetic rates and chlorophyll concentrations. Archives of Hydrobiology Special Issues on Advanced Limnology, 53, 159-178.

IPCC (2007) Climate Change 2007: The Physical Science Basis. Summary for Policymakers. Intergovernmental Panel on Climate Change: Geneva. Available from http:// www.ipcc.ch/SPM2feb07.pdf (accessed 28 October 2008).

Jankowski T, Livingstone DM, Buhrer H, Forster R, Niederhauser P (2006) Consequences of the 2003 European heat wave for lake temperature profiles, thermal stability, and hypolimnetic oxygen depletion: implications for a warmer world. Limnology and Oceanography, 51, 815-819.

Jöhnk KD, Huisman J, Sharples J, Sommeijer B, Visser PM, Stroom JM (2008) Summer heatwaves promote blooms of harmful cyanobacteria. Global Change Biology, 14, 495-512

Kamjunke N, Straile D, Gaedke U (2009) Response of heterotrophic bacteria, autotrophic picoplankton and heterotrophic nanoflagellates to re-oligotrophication. Journal of Plankton Research, 31, 899-907.

Kümmerlin RE (1998) Taxonomical response of the phytoplankton community to upper lake Constance (Bodensee-Obersee) to eutrohication and re-oligotrophication. Archives of Hydrobiology Special Issues on Advanced Limnology, 53, 109-117.

Livingstone DM (1997) An example of the simultaneous occurrence of climate-driven "sawtooth" deep-water warming/cooling episodes in several Swiss lakes. Verhandlungen Internationale Vereinigung für theoretische und angewandte Limnologie, 26, 822-826.

Luterbacher J, Liniger MA, Menzel A et al. (2007) Exceptional European warmth of autumn 2006 and winter 2007: historical context, the underlying dynamics, and its phenological impacts. Geophysical Research Letters, 34, L12704, doi: 10.1029/ 2007GL029951.

Maignan F, Breon FM, Vermote E, Ciais P, Viovy N (2008) Mild winter and spring 2007 over western Europe led to a widespread early vegetation onset. Geophysical Research Letters, 35, L02404, doi: 10.1029/2007GL032472.

Mouthon J, Daufresne M (2006) Effects of the 2003 heatwave and climatic warming on mollusc communities of the Saône: a large lowland river and of its two main tributaries (France). Global Change Biology, 12, 441-449.

Mysterud A, Stenseth NC, Yoccoz NG, Ottersen G, Langvatn R (2003) The response of terrestrial ecosystems to climate variability associated with the North Atlantic Oscillation. In: The North Atlantic Oscillation (eds Hurrell JW, Kushnir Y, Ottersen G, Visbeck M), pp. 235-262. American Geophysical Union, Washington, DC.

Ottersen G, Planque B, Belgrano A, Post E, Stenseth NC (2001) Ecological effects of the north Atlantic oscillation. Oecologia, 128, 1-18.

Peeters F, Straile D, Lorke A, Livingstone DM (2007a) Earlier onset of the spring phytoplankton bloom in lakes of the temperate zone in a warmer climate. Global Change Biology, 13, 1898-1909.

Peeters F, Straile D, Lorke A, Ollinger D (2007b) Turbulent mixing and phytoplankton spring bloom development in a deep lake. Limnology and Oceanography, 52, 286-298.

Rutishauser T, Luterbacher J, Defila C, Frank D, Wanner H (2008) Swiss spring plant phenology 2007: extremes, a multi-century perspective, and changes in temperature sensitivity. Geophysical Research Letters, 35, L05703, doi: 10.1029/2007GL032545.

Schalau K, Rinke K, Straile D, Peeters F (2008) Temperature is the key factor explaining interannual variability of daphnia development in spring: a modelling study. Oecologia, 157, 531-543.

Schär C, Vidale PL, Luthi D, Frei C, Haberli C, Liniger MA, Appenzeller C (2004) The role of increasing temperature variability in European summer heatwaves. Nature, 427, 332-336.

Schmidt W (1928) Über die Temperatur- und Stabilitätsverhältnisse von Seen. Geografiska Annaler, 10, 145-177.

Seebens H, Einsle U, Straile D (2009) Copepod life cycle adaptations and success in response to phytoplankton spring bloom phenology. Global Change Biology, 15, 1394-1404 
Straile D (2000) Meteorological forcing of plankton dynamics in a large and deep continental European lake. Oecologia, 122, 44-50.

Straile D, Eckmann R, Jüngling T, Thomas G, Löffler H (2007) Influence of climate variability on whitefish (Coregonus lavaretus) year class strength in a warm monomictic lake. Oecologia, 151, 521-529.

Straile D, Geller W (1998) Crustacean zooplankton in lake Constance from 1920 to 1995: response to eutrophication and reoligotrophication. Archives of Hydrobiology Special Issues on Advanced Limnology, 53, 255-274 American Geophysical Union, Washington, DC.

Straile D, Joehnk K, Rossknecht H (2003a) Complex effects of winter warming on the physico-chemical characteristics of a deep lake. Limnology and Oceanography, 48, 1432-1438.

Straile D, Livingstone DM, Weyhenmeyer GA, George DG (2003b) The response of freshwater ecosystems to climate variability associated with the north Atlantic oscillation. In: The North Atlantic Oscillation: Climatic Significance and Environmental Impact (eds Hurrell JW, Kushnir Y, Ottersen G, Visbeck M), pp. 263-279. American Geophysical Union, Washington, DC.

Straile D, Stenseth NC (2007) The north Atlantic oscillation and ecology: links between historical time-series, and lessons regarding future climate warming. Climate Research, 34, 259-262.

Thieltges DW, Strasser M, van Beusekom JEE, Reise K (2004) Too cold to prosper winter mortality prevents population increase of the introduced American slipper limpet Crepidula fornicata in northern Europe. Journal of Experimental Marine Biology and Ecology, 311, 375-391.

Tonn WM, Paszkowski CA (1986) Size-limited predation, winterkill, and the organization of Umbra - Perca fish assemblages. Canadian Journal of Fisheries and Aquatic Sciences, 43, 194-202.
Wegner KM, Kalbe M, Milinski M, Reusch TBH (2008) Mortality selection during the 2003 European heat wave in three-spined sticklebacks: effects of parasites and MHC genotype. BMC Evolutionary Biology, 8, 124.

Weyhenmeyer GA, Blenckner T, Pettersson K (1999) Changes of the plankton spring outburst related to the north Atlantic oscillation. Limnology and Oceanography, 44 1788-1792.

\section{Supporting Information}

Additional Supporting Information may be found in the online version of this article:

Appendix S1. Results of exchange simulation experiments on the importance of summer and autumn meteorology for water temperature dynamics during w06/07.

Please note: Wiley-Blackwell are not responsible for the content or functionality of any supporting materials supplied by the authors. Any queries (other than missing material) should be directed to the corresponding author for the article. 
Straile et al. (2010) Effects of a half a millennium winter on a deep lake a shape of things to come? Global Change Biology

\section{Supporting information}

Results of exchange simulation experiments on the importance of summer and autumn meteorology for water temperature dynamics during w06/07

The importance of meteorology prior to December 2006 for w06/07 water temperature dynamics was analyzed by exchanging the meteorology of summer and autumn 2006 with that of summer and autumn 2005 for time periods of variable length, e.g., November or June October. This experiment showed that as compared to the standard simulation no large differences in water temperature occurred during w05/06 when exchanging June - October although this strongly affected epilimnetic and metalimnetic water temperatures in summer (Fig. S1 B, F). In contrast, an exchange of November meteorology had strong effects lasting throughout the winter (Fig. S1 C, G). Lower 2005 November temperatures in the second half of November (Fig. S1 E, the first part of November 2005 was actually warmer then the first part of November 2006) would have resulted into enhanced cooling from this point onwards with consequences for water temperatures continuing until the next spring. This suggests that the rather high air temperatures from the $2^{\text {nd }}$ half of November 2006 until March 2007 but not the temperatures from June to October 2006 are important in understanding w06/07 dynamics.

Fig. S1 A) Air temperatures (7 day moving average) during the periods from May 2005 until April 2006 and May 2006 until April 2007, B) results of the standard simulation from May 2006 until April 2007, C) Simulation results of the exchange of June to October 2006 meteorology with June to October 2005 meteorology, D) Simulation results of the exchange of November 2006 meteorology with November 2005 meteorology, E) Daily differences in air temperature (7 day moving average) between the two time periods shown in A, F) Depth and time specific differences in water temperatures between the simulations shown in $\mathrm{B}$ and C,G) Depth and time specific differences in water temperatures between the simulations shown in B and D. Please note, that maximum and minimum temperature differences extend the limits of the colour coding. 
Straile et al. (2010) Effects of a half a millennium winter on a deep lake a shape of things to come? Global Change Biology

Fig. S1
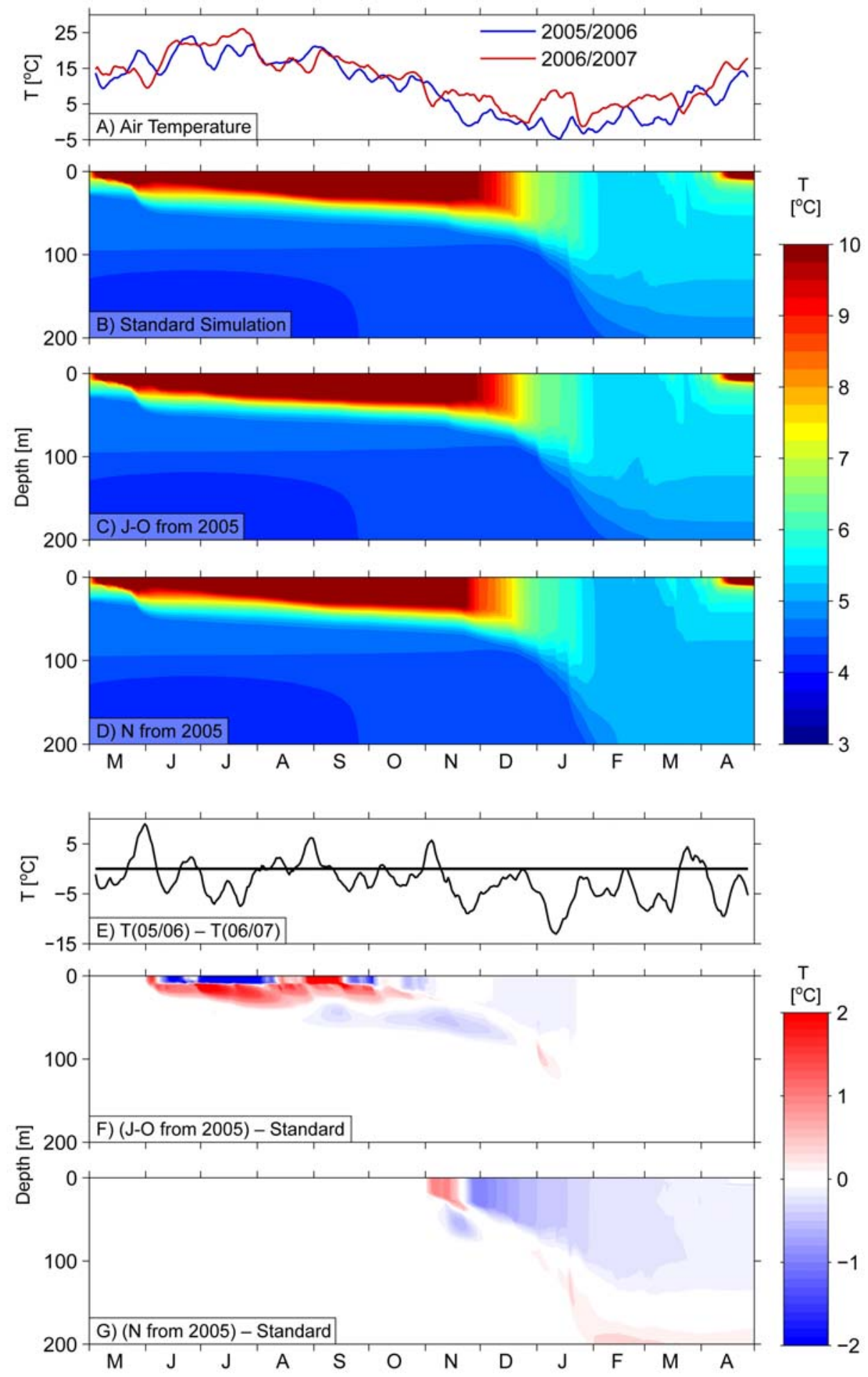